\title{
Comparative Evaluation of SARS-CoV-2 Rapid Immunochromatographic Test Assays with Chemiluminescent Immunoassay for the Diagnosis of COVID-19
}

Ghada Ismail $^{1,2}$, RaniaAbdel Halim $^{1}$, Marwa Salah Mostafa ${ }^{3}$, Dalia HAbdelhamid ${ }^{1}$, HossamAbdelghaffar $^{4,5}$, Nashwa Naguib Omar $^{1}$, Noha Alaa Eldin Fahim ${ }^{1 *(D)}$

${ }^{1}$ Department of Clinical Pathology, Faculty of Medicine, Ain Shams University, Cairo, Egypt; ${ }^{2}$ Director of Reference Laboratory of the Egyptian University Hospitals, Egypt; ${ }^{3}$ Department of Medical Microbiology and Immunology, Faculty of Medicine, Cairo University, Cairo, Egypt; ${ }^{4}$ Department of ENT, Faculty of Medicine, Helwan University, Egypt; ${ }^{5}$ Secretary General of the Supreme Council for University Hospitals, Egypt

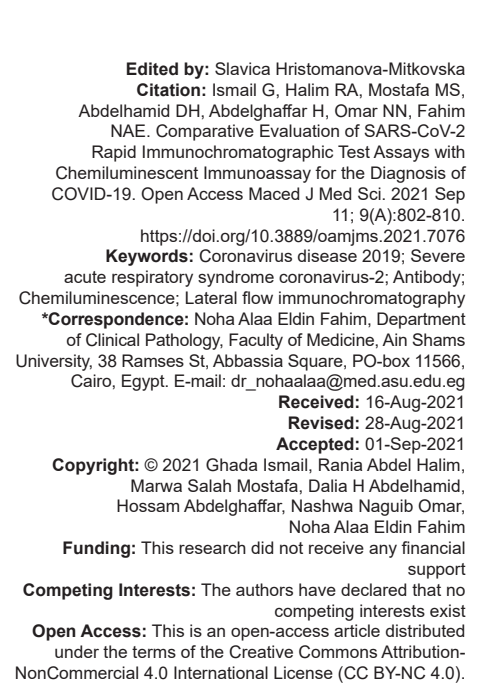

\section{Background}

The World Health Organization (WHO), on January 12, 2020, has declared the novel severe acute respiratory syndrome coronavirus 2 (SARS-CoV-2) as the incriminated causative agent of a respiratory illness that has been, later on, named coronavirus disease 2019 (COVID-19). This respiratory illness has first appeared in Wuhan City in China by the end of 2019 [1]. COVID-19 has a wide range of manifestations ranging from asymptomatic infection, mild disease of the upper respiratory system, severe viral pneumonia with an acute respiratory syndrome, to even death [2]. One of the major challenges of COVID-19 to public health is

\begin{abstract}
(Co date, the molecular assay is the gold-standard method for coronavirus disease 2019 COVID- 19) diagnosis. However, they are expensive and complex. There is a pressing necessity for developing of diagnostics for severe acute respiratory syndrome coronavirus (SARS-CoV)-2 patients. Therefore, serological detection of antibodies against SARS-CoV-2 might provide a good alternative.

immunoassay as a reference method for SARS-CoV-2 antibodies detection.

METHODS: This study included the serum of a total of 49 attendees to the Reference Laboratory of Egyptian university hospitals during the period from April 2021 to May 2021. Anti-COVID-19 antibodies detection in serum

RESULTS: The chemiluminescent assay revealed $30(61.2 \%)$ positive samples and $19(38.8 \%)$ negative samples for COVID-19 immunoglobulin (lg) G. For COVID-19 IgM, 11 (22.4\%) samples were positive and 38 (77.6\%) samples were negative. Anti-SARS-CoV-2 antibodies were not detected in any of the PCR-negative individuals. The best by Panbio. For Roche, the sensitivity and specificity for $\lg$ and $\lg M$ were $(83.3 \%$ and $89.5 \%)$ and $(72.7 \%$ and $81.6 \%)$, respectively. Vazyme showed sensitivity and specificity for $\operatorname{lgG}$ and $\operatorname{lgM}$ were $(77.8 \%$ and $85.7 \%)$ and $(75 \%$ and $91.7 \%$ ), respectively. Regards Panbio, the sensitivity and specificity for IgG and IgM were $(63.6 \%$ and $87.5 \%)$ and $(50 \%$ and $86.7 \%)$ respectively. Cohen's Kappa values revealed a substantial agreement for Roche IgG, Vazyme g G and IgM of $(0.7076,0.6250,0.6667)$ respectively. The worst agreement was reported for Maccura IgG, Wondfo, Dynamiker IgM with Cohen's Kappa values of $(0.2508,0.1893$, and 0.0313$)$, respectively.

NS: Rapid tests in our study exhibited heterogeneous diagnostic performances. Roche, Vazyme, and Panbio antibody tests showed promising results in concordance with our reference method with the best-reported results. On the other hand, the other tests were inferior and failed in providing valid and reliable results. Further studies are necessary to determine the practicality of these tests in different settings and communities.
\end{abstract}

the asymptomatic or subclinical infections which serve as silent sources rapidly spreading the infection among the community. By June 28, there were 9.8 million confirmed cases worldwide [3]. It is noted that the declared number of COVID-19 cases and deaths are increasing especially with the subsequent waves [4].

Rapid diagnosis and isolation of cases are the cornerstones for reducing COVID-19 transmission. To date, the detection of SARS-CoV-2 ribonucleic acid (RNA) from upper or lower respiratory specimens by the real-time reverse transcriptase polymerase chain reaction (real-time $\mathrm{RT}$-PCR) assay is the goldstandard method for COVID-19 diagnosis [5], [6]. The characterizing features of molecular diagnostics are their extreme sensitivity and specificity along with their 
capacity for quantitative detection of the SARS-CoV-2 RNA. However, they are expensive, relatively slow to deliver, complex, and require advanced analytical instruments and trained personnel [7]. Results also depend on the quality of the taken sample, the extracted RNA, the RT-PCR reagents, and the multi-stepped RNA preparation. In addition, the positivity rate varies with sample type (1-93\%) and viral load fluctuation at different disease phases [8].

There is a pressing necessity for developing and evaluating other effective diagnostic methods of SARS-CoV-2 patients [9]. Immunoglobulin ( $\mathrm{lg}) \mathrm{M}$ is known for its role as the first line of defence against viral infections. On the other hand, high-affinity IgG secondary responses are those providing long-term immunity [10]. Studies on SARS-CoV-2 revealed that antibodies are detectable in $80-100 \%$ of patients 2 weeks after illness onset [11]. Therefore, serological detection of antibodies against SARS-CoV-2 provides another method for the diagnosis of COVID-19 [12].

Chemiluminescence immunoassays (CLIA) are quantitative serological assays for antibody detection with high sensitivity and specificity. The continuous detection of antibody concentrations can be a useful tool for assessing both the progression of COVID-19 cases and their immune status [6]. This method is advantageous for being of high throughput and low complexity. Furthermore, it has served us to accurately use serological tests during the antibody development and monitoring different infection phases. In fact, obtaining information about the different antibody concentrations and the time kinetics of humoral response is extremely important for diagnostic, prognostic, and therapeutic purposes [13].

At the same time, a substantial number of point-of-care rapid lateral flow immunoassay test kits are being marketed [14]. These rapid tests make use of capillary or venous whole blood, plasma, or serum, and they are designed to qualitatively detect antibodies against SARS-CoV-2. Rapid results are available after 10-15 $\min [15]$.

The aim of this study was to compare and evaluate seven rapid diagnostic tests with chemiluminescent automated immunoassay test for the detection of SARS-CoV-2 antibodies.

\section{Materials and Methods}

\section{Study population}

In total, 49 attendees of the outpatient clinic at the Reference Laboratory of Egyptian university hospitals (RLEUH) were enrolled in this study. The study participants included 7 (14.3\%) females and $42(85.7 \%)$ males, with age ranging from 13 to 60 years with a mean of $37.8 \pm 10.15$ years. Participants in this study were divided into two groups: those with positive RT-PCR $(n=36)$ for SARS-CoV-2 and those with negative RT-PCR ( $n=13$ ) for SARS-CoV-2. All the PCR-positive cases produced either IgG or IgM or both, whereas anti-SARS-CoV-2 antibodies were not detected in any of the PCR-negative individuals. The study was conducted during the period from April 2021 to May 2021. An informed consent was obtained from each participant, and the study was approved by the Ethics Committee of the Supreme Council of University Hospitals 2020.

\section{Collection of serum samples}

One serum sample was collected as per each participant. Sample collection time was, on average, 20 days after a positive PCR result for the PCRconfirmed COVID-19 cases. Serum samples were stored at $-80^{\circ} \mathrm{C}$ until use.

\section{Serological assays for the detection of antibodies against SARS-CoV-2}

\section{CLIA}

All serum samples were tested to detect antibodies against SARS-CoV-2 IgG/lgM by Mindray fully automated analyzer (Shenzhen Mindray Bio-Medical Electronics Co, China) according to the manufacturer's instructions. CLIA has been considered the reference method for the evaluation of immunochromatography strip assays.

The Mindray SARS-CoV-2 IgG or IgM assay is a chemiluminescent immunoassay for the qualitative determination of SARS-CoV-2 IgG or IgM antibodies in human serum or plasma from suspected COVID19 patients. The procedure was performed according to the manufacturer's protocol for the device.

Interpretation of the test results was done as per the manufacturer's instructions. As for IgG, specimens with results $<10.00 \mathrm{U} / \mathrm{mL}$ are considered negative. While specimens with results more than or equal to $10.00 \mathrm{U} /$ $\mathrm{mL}$ are considered positive. For IgM, specimens with a cutoff index $(\mathrm{COI})<1.00 \mathrm{U} / \mathrm{mL}$ are negative for IgM antibodies to SARS-CoV-2. Moreover, specimens with a COI more than or equal to $1.00 \mathrm{U} / \mathrm{mL}$ are considered positive for IgM antibodies to SARS-CoV-2.

\section{assay (LFA) \\ Lateral flow immunochromatographic}

In this study, seven rapid lateral flow immunochromatographic antibody assays were utilized for qualitative rapid SARS-CoV-2 IgM/ IgG antibody detection: SARS-CoV-2 Antibody 
Test Wondfo (Guangzhou Wondfo Biotech, China), Vazyme 2019-nCoV IgG/lgM detection kit colloidal Gold Based (Nanjing Vazyme Medical Technology, China), Dynamiker Biotechnology 2019-nCOVIgG/ IgM Rapid test (Tianjin, China), SARS-CoV-2 IgM/ IgG rapid test kit (Maccura, China), PANBIO ${ }^{\mathrm{TM}}$ COVID-19 lgG/lgM RAPID TEST DEVICE (Abbott, USA), Artron COVID-19 IgG/IgM Antibody Rapid Test Kit (Artron laboratories, Canda), SARS-CoV-2 Rapid Antibody Test Roche ((Roche Diagnostics, Switzerland).

All the above-mentioned kits could detect SARS-CoV-2 IgM and IgG separately except for Wondfo which detects total antibodies $\lg \mathrm{G}+\lg \mathrm{M}$.

The tests were performed in accordance to the manufacturer's instructions and interpreted as follow: the presence of only the control line indicated a negative result. Whereas, the presence of both control line and either IgG or IgM antibody line or control line and total antibody test line in Wondfo Test indicated a positive result for IgG or IgM or total antibody, respectively. A weakly positive result (any shade of color in the test lines) of an antibody rapid testing was considered positive according to the manufacturers' instructions. The interpretation of the results was done by two observers.

\section{Statistical analysis}

Data were analyzed using the statistical package Statistical Package for the Social Sciences software version 25. Frequency (count) and relative frequency (percentage) were used for the categorical data. The sensitivity, specificity, positive predictive value, and negative predictive value were calculated, along with the $95 \%$ confidence interval. The measurement agreements between different antibody tests were evaluated with Cohen's kappa (к) statistics. The comparison between the categorical data was done using the Chi-square $\left(\chi^{2}\right)$ test. Fisher's exact test was used instead when the expected frequency is $<5 . p \leq 0.05$ was considered statistically significant.

\section{Results}

A total of 49 serum samples were examined for COVID-19 IgG and IgM by chemiluminescent assay (Mindray) taken as our reference method- and seven different rapid LFA antibody tests.

Not all the 49 samples were analyzed by all rapid antibody tests owing to their unavailability. For Panbio, Vazyme, and Maccura only 19, 16 and 34 tests were available respectively.

\section{Results of detection of SARS-CoV-2} antibodies by CLIA

Our reference chemiluminescent assay revealed $30(61.2 \%)$ positive samples and 19 (38.8\%) negative samples for COVID-19 IgG. For COVID-19 IgM, $11(22.4 \%)$ samples were positive and 38 (77.6\%) samples were negative. As for the 36 PCR-confirmed positive cases, 25 samples were positive for COVID-19 IgG only, six samples were positive solely for lgM, and five samples tested positive for both COVID-19 IgG and IgM. All the 13 PCR-confirmed negative cases were negative for $\lg G$ and $\lg M$ antibodies.

\section{Performance of results of detection of SARS-CoV-2 antibodies by the seven LFA antibody tests}

Itwasnoted thaton comparing chemiluminescent assay to the seven different COVID-19 rapid antibody tests, the specificity for detection of $\lg G$ was higher than that for IgM in almost all antibody tests except for Vazyme assay which showed higher specificity for the detection of IgM $(91.7 \%)$. The reported specificity for lgG ranged from $(71.4 \%)$ for Maccura up to $(100 \%)$ for Wondfo. With exception of Roche $\lg G$ and $\lg M$, Vazyme $\lg G$ and $\operatorname{lgM}$, and Maccura IgM, the reported sensitivity for all other assays was less than $70 \%$. The best diagnostic performance was demonstrated by Roche IgG and IgM, and Vazyme IgG and IgM antibody tests followed by Panbio. For Roche, the sensitivity and specificity for lgG were $83.3 \%$ and $89.5 \%$, respectively, and $72.7 \%$ and $81.6 \%$ for IgM, respectively. Vazyme showed sensitivity and specificity of $77.8 \%$ and $85.7 \%$ for $\lg$ and $75 \%$ and $91.7 \%$ for IgM, respectively. Regards Panbio, the sensitivity and specificity were $63.6 \%$ and $87.5 \%$ for $\lg G$ and $50 \%$ and $86.7 \%$ for IgM, respectively. None of the specimens resulted as an invalid test which would be indicated by a lack of the control line.

Regarding the agreement between the seven rapid LFA COVID-19 antibody tests and chemiluminescent assay (Mindray), Cohen's Kappa values revealed a substantial agreement for Roche $\lg$, Vazyme $\operatorname{lgG}$ and $\lg \mathrm{M}$ of $(0.7076,0.6250$, and $0.6667)$, respectively. The worst agreement was reported for Maccura IgG, Wondfo, and Dynamiker IgM with Cohen's Kappa values of $(0.2508,0.1893$, and 0.0313), respectively. Agreement between COVID-19 IgG and IgM by CLIA and the seven LFA rapid COVID19 antibody tests and their diagnostic performances are summarized in (Tables 1 and 2).

\section{Relation between the IgG antibody titers detected by CLIA and results of the seven LFA rapid antibody tests}

We divided the samples into four groups according to the IgG titers obtained by CLIA. Group 1 
Table 1: Correlation between COVID-19 IgG and IgM by chemiluminescence assay and the seven studied COVID-19 rapid antibody tests

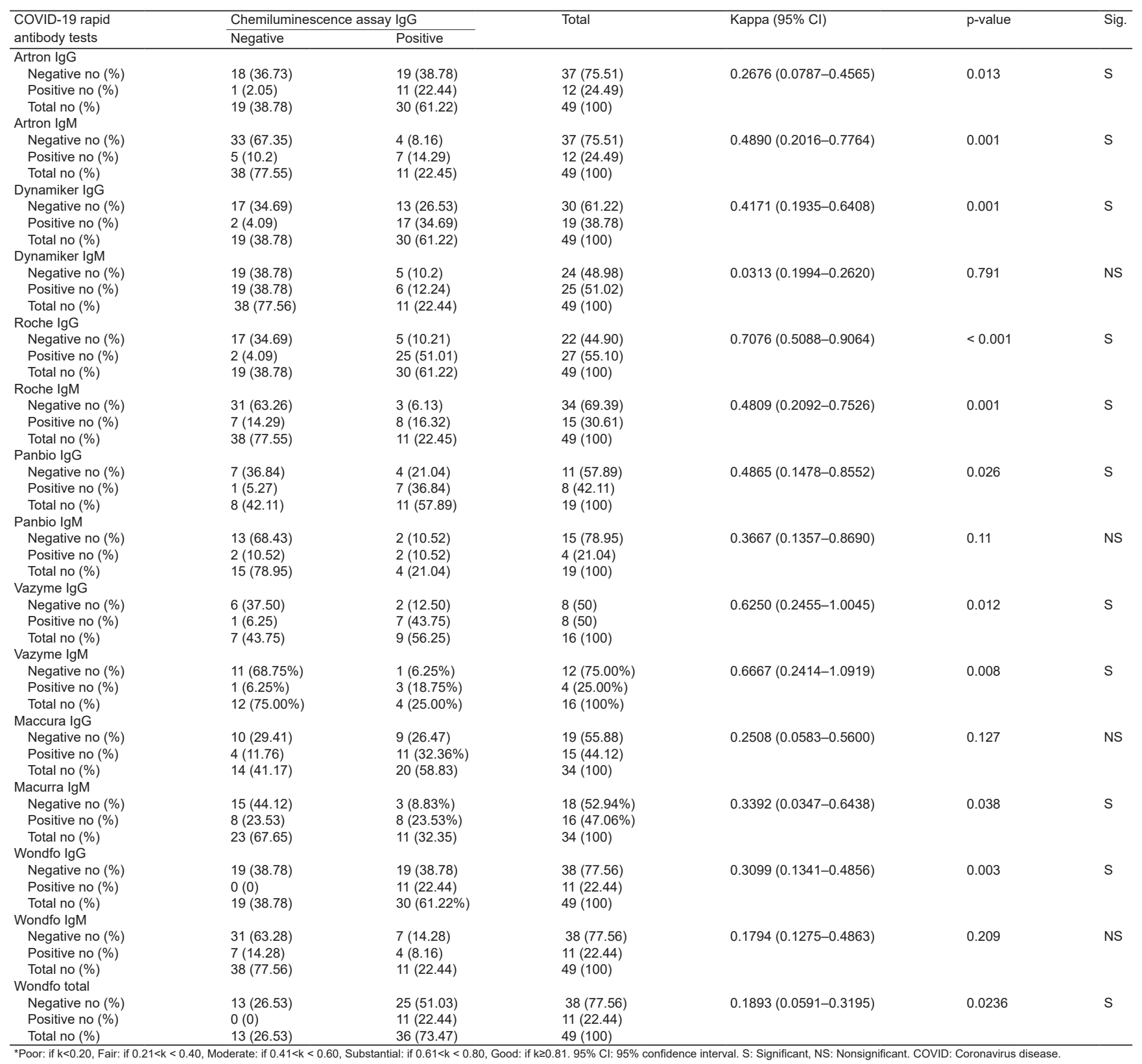

Table 2: Diagnostic performance of the studied COVID-19 rapid antibody tests compared to chemiluminescence assay as a reference method

\begin{tabular}{|c|c|c|c|c|c|}
\hline Covid-19 antibody detection LFT kits & Sensitivity (\%) $(95 \% \mathrm{Cl})$ & Specificity (\%) $(95 \% \mathrm{Cl})$ & PPV (\%) $(95 \% \mathrm{Cl})$ & NPV (\%) $(95 \% \mathrm{Cl})$ & Accuracy $(\%)(95 \% \mathrm{Cl})$ \\
\hline \multicolumn{6}{|l|}{ Artron } \\
\hline $\lg G$ & $36.7(0.1993-0.5614)$ & $94.7(0.7397-0.9987)$ & $91.7(0.6152-0.9979)$ & $48.6(0.3192-0.6560)$ & $59.18(0.4421-0.7300)$ \\
\hline $\lg M$ & $63.6(0.3079-0.8907)$ & $86.9(0.7191-0.9559)$ & $58.3(0.2767-0.8483)$ & $89.2(0.7458-0.9697)$ & $81.63(0.6798-0.9124)$ \\
\hline \multicolumn{6}{|l|}{ Dynamiker } \\
\hline $\lg G$ & $56.7(0.3743-0.7454)$ & $89.5(0.6686-0.9780)$ & $89.47(0.6686-0.9870)$ & $56.7(0.3743-0.7454)$ & $69.39(0.5458-0.8175)$ \\
\hline $\lg M$ & $54.5(0.2338-0.8325)$ & $50(0.3338-0.6662)$ & $24(0.0936-0.4513)$ & $79.2(0.5785-0.9287)$ & $51.02(0.3634-0.6558)$ \\
\hline \multicolumn{6}{|l|}{ Roche } \\
\hline $\lg G$ & $83.3(0.6528-0.9436)$ & $89.5(0.6686-0.9870)$ & $92.6(0.7571-0.9909)$ & $77.3(0.5463-0.9218)$ & $85.71(0.7276-0.9406)$ \\
\hline $\lg M$ & $72.7(0.3903-0.9398)$ & $81.6(0.6567-0.9226)$ & $53.3(0.2659-0.7873)$ & $91.2(0.7632-0.9814)$ & $79.59(0.6566-0.8976)$ \\
\hline \multicolumn{6}{|l|}{ Panbio } \\
\hline $\lg G$ & $63.6(0.3079-0.8907)$ & $87.5(0.4735-0.9968)$ & $87.5(0.4735-0.9968)$ & $63.6(0.3079-0.8907)$ & $73.68(0.4880-0.9085 \mid)$ \\
\hline $\lg M$ & $50(0.0676-0.934)$ & $86.7(0.5954-0.9834)$ & $50(0.0676-0.9324)$ & $86.7(0.5954-0.9834)$ & $78.95(0.5443-0.9395)$ \\
\hline \multicolumn{6}{|l|}{ Vazyme } \\
\hline $\lg G$ & $77.8(0.3999-0.9719)$ & $85.7(0.4213-0.9964)$ & $87.5(0.4735-0.9968)$ & $75(0.3491-0.9681)$ & $81.25(0.5435-0.9595)$ \\
\hline $\lg M$ & $75(0.1941-0.9937)$ & $91.7(0.6152-0.9979)$ & $75(0.1941-0.9937)$ & $91.7(0.6152-0.9979)$ & $87.50(0.6165-0.9845)$ \\
\hline \multicolumn{6}{|l|}{ Maccura } \\
\hline $\lg G$ & $55(0.3153-0.7694)$ & $71.4(0.4190-0.9161)$ & $73.3(0.4490-0.9221)$ & $52.6(0.2886-0.7555)$ & $61.76(0.4356-0.7783)$ \\
\hline $\lg M$ & $72.7(0.3903-0.9398)$ & $65.2(0.4273-0.8362)$ & $50(0.2465-0.7535)$ & $83.3(0.5858-0.9642)$ & $67.65(0.4947-0.8261)$ \\
\hline \multicolumn{6}{|l|}{ Wondfo } \\
\hline $\lg G$ & $36.7(0.1993-0.5614)$ & $100(0.8235-0.100)$ & 100 & $50(0.3338-0.6662)$ & $61.22(0.4624-0.7480)$ \\
\hline IgM & $36.4(0.1093-0.6921)$ & $81.6(0.6567-0.9226)$ & $36.4(0.1093-0.6921)$ & $81.6(0.6567-0.9226)$ & $71.43(0.5674-0.8342)$ \\
\hline Total & $30.56(0.1635-0.4811)$ & $100(0.7529-0.100)$ & 100 & $34.21(0.1963-0.5135)$ & $48.98(0.3442-0.6366)$ \\
\hline
\end{tabular}


represented the negative group with titer $(0-<10)$, groups 2, 3, and 4 are those with positive results with titer ranges of $(10-<50),(50-100)$, and (>100) respectively.

We calculated the sensitivities exhibited by each of the seven LFA rapid antibody tests among each IgG titer group. From the results obtained, we deduced that the higher the IgG titer, the better the sensitivity of LFA rapid tests. However, for both Panbio and Maccura, the highest sensitivity was noticed in group 3 unlike the rest of the tests. It is also worth noting that Roche test was the only kit that exhibited a reasonable sensitivity for group two $(77.8 \%)$ with high sensitivities for both groups 3 and $4(83.3 \%, 100 \%)$. The rest of the results are summarized in Table 3.

Unfortunately, IgM titer levels in our study were low and very close to each other thus, we could not categorize them into different groups.

\section{Discussion}

The outraging COVID-19 situation has imposed the need for antibody testing of large populations, to determine the seroprevalence and potential immunity [16].

WHO recommends using molecular assays for the diagnosis of COVID-19. However, lack of supplies has made such diagnostic tests inaccessible to all those in need. Hence, serological testing was developed to broaden laboratories testing capacity so it can reach all the population [17]. In addition to its complementary role to the RT-PCR for the diagnosis of COVID-19, a serological assay is identified as a beneficial tool for detecting SARS-CoV-2 specific antibodies. This can aid in roughly calculating infection rate and virus prevalence among a population, estimating protection against reinfection, and evaluating the effectiveness of various vaccines. To achieve these goals, many automated and point-of-care serological tests have been produced [18], [19].

At present, antibody levels are mostly quantified by the enzyme-linked immunosorbent assay and CLIA technologies. These methods, although valid, are time needy and mandate venous sampling. Furthermore, they necessitate specified and expensive equipment with skillful operators [20].

In contrast, rapid tests for SARS-CoV-2 antibodies determination are easy to use and require 15 min for the test. Among these are the LFAs that may facilitate SARS-CoV-2 diagnosis. In fact, these tests are styled to be rapid, sensitive, highly accessible, and easily performed, requiring only a small amount of blood making them suitable for point of care testing (POCT) [18], [21]. Therefore, it has the potentiality to be deployed in largescale serological surveys [22]. However, validation for such assays is necessary before approving them as a diagnostic tool for detecting SARS-CoV-2. Therefore, more studies need to be conducted for evaluating the diagnostic performance of the serologic test launched to the international market [19], [23].

In the current study, we compared the results of seven rapid tests for detecting SARS-CoV-2 IgM and IgG with the Mindray CLIA fully automated analyzer,

Table 3: Performance of the studied LFA rapid tests in the four IgG titer groups

\begin{tabular}{|c|c|c|c|c|c|c|}
\hline \multirow[t]{2}{*}{ LFA rapid tests } & \multicolumn{5}{|c|}{ Chemiluminescence IgG value groups } & \multirow[t]{2}{*}{$\mathrm{p}$-value } \\
\hline & Group $1(0-<10)$ & Group $2(10-<50)$ & Group 3 (50-100) & Group 4 (>100) & Total & \\
\hline \multicolumn{7}{|l|}{ Artron IgG } \\
\hline Negative no (\%) & $18(94.7)$ & $14(77.8)$ & $4(66.7)$ & $1(16.7)$ & $37(75.5)$ & \multirow[t]{4}{*}{0.02} \\
\hline Positive no (\%) & $1(5.3)$ & $4(22.2)$ & $2(33.3)$ & $5(83.3)$ & $12(24.5)$ & \\
\hline Total no (\%) & $19(100)$ & $18(100)$ & $6(100)$ & $6(100)$ & $49(100)$ & \\
\hline Sensitivity (\%) & NA & 22.22 & 33.33 & 83.33 & 36.7 & \\
\hline \multicolumn{7}{|l|}{ Wondfo IgG } \\
\hline Negative no (\%) & $19(100.0)$ & $13(72.2)$ & $4(66.7)$ & $2(33.3)$ & $38(77.6)$ & \multirow[t]{4}{*}{0.05} \\
\hline Positive no (\%) & $0(0.0)$ & $5(27.8)$ & $2(33.3)$ & $4(66.7)$ & $11(22.4)$ & \\
\hline Total no (\%) & $19(100)$ & $18(100)$ & $6(100)$ & $6(100)$ & $49(100)$ & \\
\hline Sensitivity (\%) & NA & 27.8 & 33.3 & 66.7 & 30.56 & \\
\hline \multicolumn{7}{|l|}{ Dynamiker IgG } \\
\hline Negative no (\%) & 17 (89.5) & $12(66.7)$ & $1(16.7)$ & $0(0.0)$ & $30(61.2)$ & \multirow[t]{3}{*}{$<0.001$} \\
\hline Positive no (\%) & $2(10.5)$ & $6(33.3)$ & $5(83.3)$ & $6(100)$ & $19(38.8)$ & \\
\hline Total no (\%) & $19(100)$ & $18(100)$ & $6(100)$ & $6(100)$ & $49(100)$ & \\
\hline Sensitivity (\%) & NA & 33.3 & 83.3 & 100 & 56.7 & \\
\hline \multicolumn{7}{|l|}{ Roche IgG } \\
\hline Negative no (\%) & $17(89.5)$ & $4(22.2)$ & $1(16.7)$ & $0(0.0)$ & $22(44.9)$ & \multirow[t]{3}{*}{$<0.001$} \\
\hline Positive no (\%) & $2(10.5)$ & $14(77.8)$ & $5(83.3)$ & $6(100)$ & $27(55.1)$ & \\
\hline Total no (\%) & $19(100)$ & $18(100)$ & $6(100)$ & $6(100)$ & $49(100)$ & \\
\hline Sensitivity (\%) & NA & 77.8 & 83.3 & 100 & 77.3 & \\
\hline \multicolumn{7}{|l|}{ Panbio IgG } \\
\hline Negative no (\%) & $7(87.5)$ & $3(60.0)$ & $0(0)$ & $1(33.3)$ & $11(57.9)$ & \multirow[t]{4}{*}{0.051} \\
\hline Positive no (\%) & $1(12.5)$ & $2(40)$ & $3(100)$ & $2(66.7)$ & $8(42.10$ & \\
\hline Total no (\%) & $8(100)$ & $5(100)$ & $3(100)$ & $3(100)$ & $19(100)$ & \\
\hline Sensitivity (\%) & NA & 40 & 100 & 66.7 & 63.6 & \\
\hline \multicolumn{7}{|l|}{ Maccura lgG } \\
\hline Negative no (\%) & $10(71.4)$ & $6(54.5)$ & $1(25)$ & $2(40)$ & $19(55.9)$ & \multirow[t]{4}{*}{0.329} \\
\hline Positive no (\%) & $4(28.6)$ & $5(45.5)$ & $3(75)$ & $3(60)$ & $15(44.1)$ & \\
\hline Total no (\%) & $14(100)$ & $11(100)$ & $4(100)$ & $5(100)$ & $34(100)$ & \\
\hline Sensitivity (\%) & NA & 45.5 & 75 & 60 & 55 & \\
\hline \multicolumn{7}{|l|}{ Vazyme IgG } \\
\hline Negative no (\%) & $6(85.7)$ & $2(66.7)$ & $0(0.0)$ & $0(0.0)$ & $8(50)$ & \multirow[t]{4}{*}{0.019} \\
\hline Positive no (\%) & $1(14.3)$ & 1 (33.3) & $3(100)$ & $3(100)$ & $8(50)$ & \\
\hline Total no (\%) & $7(100)$ & $3(100)$ & $3(100)$ & $3(100)$ & $16(100)$ & \\
\hline Sensitivity (\%) & NA & 33.3 & 100.0 & 100.0 & 77.8 & \\
\hline
\end{tabular}


as the reference method, using serum samples from both PCR-confirmed positive and negative COVID-19 attendees at RLEUH from April 2021 to May 2021.

Although the Mindray CLIA assay cannot be considered the serological gold standard test, its analytical performance has been successfully evaluated by Younes et al. (2021) and Pieri et al. 2021) [24], [25]. Younes et al. (2021) reported a total sensitivity and specificity of $90.1 \%$ and $95.3 \%$ for detecting SARSCoV-2 IgG and IgM in COVID-19 patients [24]. Pieri et al. (2021) found that Mindray anti-SARS-CoV-2 IgG and IgM assays demonstrated high sensitivity and specificity both in the early infection $(97 \%$ and $100 \%$ for $\operatorname{lgG}, 87 \%$ and $98 \%$ for lgM, respectively) and in the late infection (100\% and $100 \%$ for $\operatorname{lgG}, 83 \%$ and $98 \%$ for IgM, respectively) [25].

According to the results obtained in our study, it is obvious that the performance of the rapid LFAantibody tests from different producers varied. Generally, the highest specificity and best concordance were found for IgG detection for most of the evaluated tests. Among the seven tested rapid antibody tests, Roche (IgG and $\operatorname{lgM}$ ), Vazyme (IgG and IgM) antibody tests followed by Panbio seemed to be the most accurate with the best diagnostic performance with sensitivity rates ranging from $72.7 \%$ to $85.3 \%$ and specificity rates ranging from $81.6 \%$ to $91.7 \%$. Although Wondfo has beaten the other tests and displayed $100 \%$ specificity for the detection of total IgG and IgM, it showed a very low sensitivity of $(30.56 \%)$ with the highest number of false-negative results $(25 / 49,51.03 \%)$.

Studies evaluating the rapid COVID-19 antibody tests are infrequent. Regarding Artron, Wakita and his colleagues (2021) from Japan reported a higher specificity for IgM (99\%) compared to the present study and a closely similar specificity for IgG (91\%) [26]. Morshed et al. (2021) reported much higher average sensitivity and approximately similar specificity for $\lg$ (92.4\%, 100\%) and for $\lg M(94.9 \%, 93.5 \%)$ respectively. They found that Artron IgM cross-reacts with sera containing West Nile virus IgG, mumps IgM, and Chikungunya IgM [27]. Stein et al. (2021) noticed that the sensitivity ranged from $74.2 \%$ for samples collected less than 7 days post-symptom onset to $95.3 \%$ in samples collected more than 14 days with $96.6 \%$ specificity [28]. On the contrary, Imai et al. (2020) reported a comparable sensitivity to ours of $(42.2 \%)$ but with higher specificity (97.9\%) [29].

Previous studies demonstrated better performance of Vazyme LFA compared to our results. Xie etal. (2021) reported high sensitivity (95.9\%) and specificity $(96.1 \%)$ versus the plaque reduction neutralization test results [30]. Fujigaki et al. (2020) reported specificity of $(97 \%, 99 \%)$ for IgM and IgG respectively [31].

Haguet et al. (2021) evaluated the clinical performance of Panbio and detected a higher sensitivity for IgG (95.2\%) with a much lower sensitivity for IgM (20.5\%). Their obtained specificities were higher than ours for both $\lg G$ and $\lg M(98.7 \%, 100 \%)$ respectively [32].

Similar to our results, other studies reported low sensitivity for Wondfo. Borges et al. (2020) stated that according to their study Wondfo assay was compared with fluorescence assay and displayed a sensitivity and specificity of $11.12 \%$ and $100 \%$ respectively [17]. Similarly, Guedez-López et al. (2020) found that the overall sensitivity, specificity obtained with Wondfo were $45.2 \%$ and $81.8 \%$, respectively [23].

On the other hand, Valdivia et al. (2021) stated that Wondfo has an overall sensitivity of $91.1 \%$ [18]. Whitman et al. (2020) and Paiva et al. (2020) also found that Wondfo displayed specificity of $(99.1 \%, 100 \%)$, respectively [1], [33]. Breva et al. (2021) reported a sensitivity and specificity for Wondfo of $73.0 \%$ and $96.7 \%$ respectively [34]. Chen et al. (2020) from Taiwan found that Wondfo and Dynamiker tests displayed diagnostic sensitivities of $(91.4 \%, 90.1 \%)$ respectively after more than 21 days of symptom onset. Meanwhile, the diagnostic specificity was $100.0 \%$ for both [19]. Our findings showed much lower sensitivity of both tests.

Lau et al. (2021) evaluated two POCT Panbio and Roche. They displayed high specificity and sensitivity for Panbio and Roche of $(98.7 \%, 97.2 \%)$ and $(100 \%, 97.2 \%)$ respectively [35]. Our findings were closely similar to Roche test but were much lower for Panbio.

That noticed difference in the reported diagnostic performance of different rapid tests in different studies could be attributed to the different studied groups' characteristics, sample size, demographic data, reference methods used, and endogenous factors in samples.

La Marca et al. (2020) shared in their review a very impressive opinion that could partially explain the high performance for some tests reported by others. They mentioned that the studies outside china found much lower sensitivity than those conducted in China. This could be due to the exaggerated claims of the manufacturers just for marketing their goods. They advised giving enough time for assessing these tests before acknowledging them suitable for use [36].

Generally, rapid assays in our study -with few exceptions- have a low diagnostic performance compared with CLIA assays. This can be attributed to the technical differences between the two methodologies besides the high detection limit and low antibody concentrations in early infection and in less severe cases that may contribute to the false-negative results observed with the rapid tests [36].

It is worthy to note that the false-negative results obtained with the seven rapid tests require attention, as they may lead to missing COVID-19 cases. This can yield a false sense of security and confidence with a possibility of further COVID-19 spread [37]. Moreover, 
this can mislead policymakers to loosen social distancing measures and release population lockdown.

Several factors that can give rise to negative rapid test result in the presence of SARS-CoV-2 infection have been reported, as the presence of inhibitors and prolonged storage time can cause antibody degradation [17], [38].

Also, the test efficacy can be related to the timing of sampling after the onset of symptoms due to the different antibody levels. Some authors suggested fluctuation of sensitivity with disease progression [17]. Other potential causes that can affect the final result are the existence of some endogenous and exogenous factors as Hematocrit, triglycerides, cholesterol, hemoglobin, and sample temperature. In traditional lateral flow tests, a detectable binding degree decreases with high concentrations of nonspecific immunoglobulin [38].

Regarding false positivity, many researchers have faced the same problem and it can be imputed to a number of causes. First, the difference in labelling viral protein between serological tests might explain the absence or presence of cross-reaction with other antibodies as anti-CMV antibodies [19] and other coronaviruses [39], [40]. In our study, Wondfo Test using $S$ protein as labelling viral protein which is known for being specific did not exhibit any falsepositive results. While other tests use the less specific labelling viral protein ( $\mathrm{N}$ protein) as in the case of the Dynamiker test that can explain the high level of false positivity in IgM detection [39]. Unfortunately, the type of antigen/s is often not reported by in vitro diagnostics companies [19].

It was also found that certain rapid antibody tests for SARS-CoV-2 might cross-react with antibodies to other viruses, antinuclear antibodies, and other autoantibodies. A high concentration of rheumatoid factor IgM may intervene with COVID-19 IgM/lgG antibody detection. Other researchers described possible cross-reactivity with HIV. Other conditions as nasopharyngeal carcinoma, colon cancer, duodenal carcinoma, diabetes, diffuse bronchitis, and even pregnancy have been associated with false positivity. Due to the aforementioned reasons, it is very crucial to assess the immune status, vaccination history, and comorbidities of the patients to help interpret the results in correlation with their clinical conditions [38], [41].

In a similar way to the false-negative results, endogenous elements as hematocrit levels or other substances can influence the procedure of these rapid LFA in diverse ways resulting in false-positive results [30].

Although specific SARS-CoV-2 tests particularly in low-prevalence settings can be prioritized because of their good specificity would help rule out the infection, however, an ideal serological test should have a high diagnostic sensitivity, low or no cross-reactivity with a high sample throughput [19], [16], [42].
In the present study, we investigated the performance of the seven LFA rapid antibody tests among different IgG titer groups. The sensitivity of LFA rapid antibody tests improved with higher IgG titers; however, for both Panbio and Maccura, the highest sensitivity was noticed in group 3 . Roche test was the only one with a reasonable sensitivity in all IgG positive groups. Although some tests exhibited very low sensitivities in low titers, the numbers of samples are too small to verdict these tests non-suitable for COVID19 diagnosis. So before issuing our statement of judgment, we have to give them a chance by retesting them with a larger number of samples.

It should be noted that there were some limitations in the current study. The small sample size was our first limitation. Secondly, for all patients, sequential serum specimens were not available to study the kinetics of the antibody response. Third, due to the current pandemic situation, this has led to an interrupted availability of the tests, so it was not possible to evaluate the same number of samples for all assays. Fourth, we did not investigate variable causes of cross reactivity of the rapid tests involved in the present study. Fifth, no clinical data were available so we could not verify the clinical performance for any of the tested methods. Finally, our study targeted mainly outpatients with mild symptoms, hence, we could not establish a comparison between patients with severe disease symptoms and those with mild symptoms. As it is known, COVID-19 antibody titers tend to be lower in less severe cases.

Also, our study had some points of strength. First, we evaluated the performance of seven rapid COVID-19 antibody tests. Second, we managed to use the same specimens to compare the tests involved in the current study. Finally, we evaluated the sensitivity of the seven rapid tests among various $\lg G$ titers obtained in our study.

\section{Conclusions}

In conclusion, rapid tests in our study exhibited heterogeneous diagnostic performances. Some of them showed promising results in concordance with our reference CLIA method where Roche, Vazyme, and Panbio antibody tests displayed the best-reported results. This could justify their use in some settings, where automated assays are not available, taking into respect limitations with regards to false-negative results. On the other hand, the other tests were inferior and failed in providing valid and reliable results and appeared not to be a good alternative for automated methods. However, if the limitations of the rapid test are known, some correction factors can be used to adjust the epidemiological data. Further studies may be necessary 
to determine the practicality of these tests in different settings and communities. To grasp the grounds behind the low sensitivity of the immunochromatographic assay, we need to conduct future research to investigate the possibility of interferences of sample timing and collection with the attained result.

In light of the obtained results, we have to be cautious about the wide routine use of these tests for critical decision making for clinicians. Thus, we recommend more larger-scale studies involving patients with a wide range of symptoms. Also, we encourage the study of the antibody kinetics to enable linking the results with disease stages. In addition to the clinical data, it is mandatory to evaluate the immunological status of the studied population to help understand the cross-reactivity and avoid any possible interference in the samples.

\section{References}

1. Whitman JD, Hiatt J, Mowery CT, Shy BR, Yu R, Yamamoto TN, et al. Test performance evaluation of SARS-CoV-2 serological assays. MedRxiv. 2020. https:// doi:10.1101/2020.04.25.20074856

PMid:32511497

2. Chan JF, Yuan S, Kok KH, To KK, Chu H, Yang J, et al. A familial cluster of pneumonia associated with the 2019 novel coronavirus indicating person-to-person transmission: a study of a family cluster. Lancet. 2020;395(10223):514-23. https://doi. org/10.1016/s0140-6736(20)30154-9

PMid:31986261

3. Long QX, Liu BZ, Deng HJ, Wu GC, Deng K, Chen YK, et al. Antibody responses to SARS-CoV-2 in patients with COVID-19. Nat Med. 2020;26(6):845-8. https://doi.org/10.1038/ s41591-020-0897-1

4. Ismail G, Mostafa MS, Abdelghaffar H, Halim RA, Omar NN Fahim NAE. Current Status and a Future Perspective of COVID19 in Egypt: Egyptian Reference Laboratory Experience. J Pure Appl Microbiol. 2021;15(3):1257-65. https://doi.org/10.22207/ JPAM.15.3.15

5. Coronaviridae Study Group of the International Committee on Taxonomy of Viruses. The species Severe acute respiratory syndrome-related coronavirus: Classifying 2019-nCoV and naming it SARS-CoV-2. Nat Microbiol. 2020;5:536-44. https:// doi.org/10.1038/s41564-020-0695-z

6. Lijia S, Lihong S, Huabin W, Xiaoping X, Xiaodong L, Yixuan Z, et al. Serological chemiluminescence immunoassay for the diagnosis of SARS-CoV-2 infection. J Clin Lab Anal. 2020;34(10):e23466. https://doi.org/10.1002/jcla.23466 PMid:32671890

7. Huang C, Wang Y, Li X, Ren L, Zhao J, Hu Y, et al. Clinical features of patients infected with 2019 novel coronavirus in Wuhan, China. Lancet. 2020;395(10223):497-506. https://doi. org/10.1016/S0140-6736(20)30183-5

8. Wang P. Combination of serological total antibody and RT-PCR test for detection of SARS-COV-2 infections. J Virol Methods. 2020;283:113919. https://doi.org/10.1016/j. jviromet.2020.113919

PMid:32554043
9. Sheridan C. Fast, portable tests come online to curb coronavirus pandemic. Nat Biotechnol. 2020;38(5):515-8. https://doi. org/10.1038/d41587-020-00010-2 PMid:32203294

10. Corman VM, Albarrak AM, Omrani AS, Albarrak MM, Farah $\mathrm{ME}$, Almasri $\mathrm{M}$, et al. Viral shedding and antibody response in 37 patients with middle east respiratory syndrome coronavirus infection. Clin Infect Dis. 2016;62(4):477-83. https://doi. org/10.1093/cid/civ951

\section{PMid:26565003}

11. Racine $R$, Winslow GM. IgM in microbial infections: Taken for granted? Immunol Lett. 2009;125(2):79-85. https://doi. org/10.1016/j.imlet.2009.06.003

PMid: 19539648

12. Liu W, Liu L, Kou G, Zheng Y, Ding Y, Ni W, et al. Evaluation of nucleocapsid and spike protein-based enzyme-linked immunosorbent assays for detecting antibodies against SARSCoV-2. J Clin Microbiol. 2020;58(6):e00461-20. https://doi. org/10.1128/JCM.00461-20 PMid:32229605

13. Infantino M, Grossi V, Lari B, Bambi R, Perri A, Manneschi M, et al. Diagnostic accuracy of an automated chemiluminescent immunoassay for anti-SARS-CoV-2 IgM and IgG antibodies: An Italian experience. J Med Virol. 2020;92(9):1671-5. https://doi org/10.1002/jmv.25932

PMid:32330291

14. Xu Y, Xiao M, Liu X, Xu S, Du T, Xu J, et al. Significance of serology testing to assist timely diagnosis of SARS-CoV-2 infections: Implication from a family cluster. Emerg Microbes Infect. 2020;9(1):924-7. https://doi.org/10.1080/22221751.2020 1752610

\section{PMid:32286155}

15. Vashist SK. In vitro diagnostic assays for COVID-19: Recent advances and emerging trends. Diagnostics (Basel). 2020;10(4):202. https://doi.org/10.3390/diagnostics10040202 PMid:32260471

16. Findeisen $\mathrm{P}$, Stiegler $\mathrm{H}$, Lopez-Calle $\mathrm{E}$, Schneider T, Urlaub E, Hayer J, et al. Clinical performance evaluation of a SARSCoV-2 Rapid Antibody Test for determining past exposure to SARS-CoV-2. Int J Infect Dis. 2021;103:636-41. https://doi. org/10.1016/j.jijid.2020.11.164

PMid:33227517

17. Borges LP, De Oliveira MGB, de Souza DRV, Dos Santos KA Heimfarth $\mathrm{L}$, et al. Can the Wondfo® SARS-CoV-2 IgM/lgG antibodies be used as a rapid diagnostic test? Arch Biotechnol Biomed. 2020;4:13-7.

18. Valdivia A, Torres I, Latorre V, Francés-Gómez C, Ferrer J, Forqué $\mathrm{L}$, et al. Suitability of two rapid lateral flow immunochromatographic assays for predicting SARS-CoV-2 neutralizing activity of sera. J Med Virol. 2021;93(4):2301-6. https://doi.org/10.1002/jmv.26697

PMid:33236799

19. Chen SY, Lee YL, Lin YC, Lee NY, Liao CH, Hung YP, et al Multicenter evaluation of two chemiluminescence and three lateral flow immunoassays for the diagnosis of COVID-19 and assessment of antibody dynamic responses to SARS-CoV-2 in Taiwan. Emerg Microbes Infect. 2020;9(1):2157-68. https://doi. org/10.1080/22221751.2020.1825016 PMid:32940547

20. Plebani M, Parčina M, Bechri I, Zehender G, Terkeš V, Abde Hafith B, et al. Performance of the COVID19SEROSpeed $\mathrm{IgM} / \mathrm{lgG}$ rapid test, an immunochromatographic assay for the diagnosis of SARS-CoV-2 infection: A multicenter European study. J Clin Microbiol. 2021;59(2):e02240-20. https://doi. org/10.1128/JCM.02240-20 


\section{PMid:33218990}

21. Ko JH, Joo EJ, Kim SH, Kim YJ, Huh K, Cho SY, et al. Clinical application of rapid diagnostic test kit for SARS-CoV-2 antibodies into the field of patient care. J Microbiol Immunol Infect. 2021;54(1):97-100. https://doi.org/10.1016/j.jmii.2020.07.003 PMid:32684340

22. Ghaffari A, Meurant R, Ardakani A. COVID-19 serological tests: How well do they actually perform? Diagnostics (Basel). 2020;10(7):453. https://doi.org/10.3390/diagnostics10070453 PMid:32635444

23. Guedez-López GV, Alguacil-Guillén M, González-Donapetry P, Bloise I, Tornero-Marin C, González-García J, et al. Evaluation of three immunochromatographic tests for rapid detection of antibodies against SARS-CoV-2. Eur J Clin Microbiol Infect Dis. 2020;39(12):2289-97. https://doi.org/10.1007/ s10096-020-04010-7

PMid:32808111

24. Younes S, Al-Jighefee H, Shurrab F, Al-Sadeq DW, Younes N Dargham SR, et al. Diagnostic efficiency of three fully automated serology assays and their correlation with a novel surrogate virus neutralization test in symptomatic and asymptomatic SARS-COV-2 individuals. Microorganisms. 2021;9(2):245. https://doi.org/10.3390/microorganisms9020245 PMid:33504067

25. Pieri M, Nuccetelli M, Nicolai E, Sarubbi S, Grelli S, Bernardini S. Clinical validation of a second generation anti-SARS-CoV-2 IgG and IgM automated chemiluminescent immunoassay. J Med Virol. 2021;93(4):2523-28. PMid:33463719

26. Wakita M, Idei M, Saito K, Horiuchi Y, Yamatani K, Ishikawa S, etal. Comparison of the clinical performance and usefulness of five SARS-CoV-2 antibody tests. PLoS One. 2021;16(2):e0246536. https://doi.org/10.1371/journal.pone.0246536 PMid:33556086

27. Morshed M, Sekirov I, McLennan M, Levett PN, Chahil N, Mak A, et al. Comparative analysis of capillary vs venous blood for serologic detection of SARS-CoV-2 antibodies by RPOC lateral flow tests. Open Forum Infect Dis. 2021;8(3):ofab043. https://doi.org/10.1093/ofid/ofab043

PMid:33723509

28. Stein DR, Osiowy C, Gretchen A, Thorlacius L, Fudge D, Lang A, et al. Evaluation of commercial SARS-CoV-2 serological assays in Canadian public health laboratories. Diagn Microbiol Infect Dis. 2021;101(3):115412. https://doi.org/10.1016/j. diagmicrobio.2021.115412

29. Imai K, Tabata S, Ikeda M, Noguchi S, Kitagawa Y, Matuoka M, et al. Clinical evaluation of an immunochromatographic lgM/ IgG antibody assay and chest computed tomography for the diagnosis of COVID-19. J Clin Virol. 2020;128:104393. https:// doi.org/10.1016/j.jcv.2020.104393

PMid:32387968

30. Xie X, Nielsen MC, Muruato AE, Fontes-Garfias CR, Ren P. Evaluation of a SARS-CoV-2 lateral flow assay using the plaque reduction neutralization test. Diagn Microbiol Infect Dis. 2021;99(2):115248. https://doi.org/10.1016/j. diagmicrobio.2020.115248

PMid:33130510

31. Fujigaki $H$, Takemura M, Osawa M, Sakurai $A$, Nakamoto $K$, Seto K, et al. Reliability of serological tests for COVID-19: Comparison of three immunochromatography test kits for SARS-CoV-2 antibodies. Heliyon. 2020;6(9):e04929. https://doi. org/10.1016/j.heliyon.2020.e04929

\section{PMid:32984615}

32. Haguet H, Douxfils J, Eucher C, Elsen M, Cadrobbi J, TréHardy M, et al. Clinical performance of the Panbio assay for the detection of SARS-CoV-2 IgM and IgG in COVID-19 patients. J Med Virol. 2021;93(5):3277-81. https://doi.org/10.1002/ jmv.26884

PMid:33599299

33. Paiva KJ, Grisson RD, Chan PA, Huard RC, Caliendo AM, Lonks JR, et al. Validation and performance comparison of three SARS-CoV-2 antibody assays. J Med Virol. 2021;93(2):916-23. https://doi.org/10.1002/jmv.26341 PMid:32710669

34. Montolio Breva S, Molina Clavero C, Gómez Bertomeu F, PicóPlana E, Serrat Orús N, Palau Sánchez I, et al. Evaluation of five immunoassays and one lateral flow immunochromatography for anti-SARS-CoV-2 antibodies detection. Enferm Infect Microbio Clin (Engl Ed). 2021. https://doi.org/10.1016/j.eimc.2020.12.002 PMid:33558047

35. Lau CS, Hoo SP, Liang YL, Phua SK, Aw TC. Performance of two rapid point of care SARS-COV-2 antibody assays against laboratory-based automated chemiluminescent immunoassays for SARS-COV-2 IG-G, IG-M and total antibodies. Pract Lab Med. 2021;24:e00201. https://doi.org/10.1016/j.plabm.2021.e00201 PMid:33501369

36. La Marca A, Capuzzo M, Paglia T, Roli L, Trenti T, Nelson SM Testing for SARS-CoV-2 (COVID-19): A systematic review and clinical guide to molecular and serological in-vitro diagnostic assays. Reprod Biomed Online. 2020;41(3):483-99. https://doi org/10.1016/j.rbmo.2020.06.001

PMid:32651106

37. Swadźba J, Bednarczyk M, Anyszek T, Martin E. A comparison of 7 commercial anti-SARS-CoV-2 antibody immunoassays. Arch Med Sci. 2020. https://doi.org/10.5114/aoms.2020.98361

38. Mouliou DS, Gourgoulianis KI. False-positive and false-negative COVID-19 cases: Respiratory prevention and management strategies, vaccination, and further perspectives. Expert Rev Respir Med. 2021;15(8):993-1002. https://doi.org/10.1080/174 76348.2021.1917389

PMid:33896332

39. Gambino CM, Lo Sasso B, Colomba C, Giglio RV, Agnello L, Bivona $\mathrm{G}$, et al. Comparison of a rapid immunochromatographic test with a chemiluminescence immunoassay for detection of anti-SARS-CoV-2 IgM and IgG. Biochem Med (Zagreb). 2020;30(3):030901.

PMid:33071558

40. Augustine R, Das S, Hasan A, Abhilash S, Abdul Salam S, Augustine $\mathrm{P}$, et al. Rapid antibody-based COVID-19 mass surveillance: Relevance, challenges, and prospects in a pandemic and post-pandemic world. J Clin Med. 2020;9(10):3372. https://doi.org/10.3390/jcm9103372 PMid:33096742

41. Jia $X$, Xiao L, Liu Y. False negative RT-PCR and false positive antibody tests-Concern and solutions in the diagnosis of COVID- 19. J Infect. 2021;82(3):414-51. https://doi. org/10.1016/j.jinf.2020.10.007

PMid:33039501

42. Pegoraro M, Militello V, Salvagno GL, Gaino S, Bassi A, Caloi C, et al. Evaluation of three immunochromatographic tests in COVID-19 serologic diagnosis and their clinical usefulness. Eur J Clin Microbiol Infect Dis. 2021;40(4):897-900. https://doi. org/10.1007/s10096-020-04040-1

PMid:33078222 